\title{
Susceptibility of Walnut and Hickory Species to Geosmithia morbida
}

\author{
Curtis Utley, Bioagricultural Sciences and Pest Management, Colorado State University, Ft. Collins; Tivonne Nguyen and Tatiana \\ Roubtsova, Department of Plant Pathology, University of California, Davis; Mark Coggeshall, Department of Forestry/Center for \\ Agroforestry, University Missouri, Columbia; Tim M. Ford, Improving Perennial Plants for Food and Bioenergy, Inc., Hyde Park, UT; \\ L. J. Grauke, United States Department of Agriculture (USDA) Agricultural Research Service Pecan Breeding \& Genetics, Somerville, \\ TX; Andrew D. Graves, USDA Forest Service, Forest Health Protection, Albuquerque, NM; Charles A. Leslie, Walnut Improvement \\ Program, Department of Plant Sciences, University of California, Davis; James McKenna and Keith Woeste, USDA Forest Service \\ Hardwood Tree Improvement and Regeneration Center, Department of Forestry and Natural Resources, Purdue University, West \\ Lafayette, IN; Mohammad A. Yaghmour, Department of Plant Pathology, University of California, Davis; Whitney Cranshaw, \\ Bioagricultural Sciences and Pest Management, Colorado State University, Ft. Collins; Steven J. Seybold, USDA Forest Service, \\ Pacific Southwest Research Station, Davis, CA; Richard M. Bostock, Department of Plant Pathology, University of California, Davis; \\ and Ned Tisserat, Bioagricultural Sciences and Pest Management, Colorado State University, Ft. Collins
}

\begin{abstract}
Utley, C., Nguyen, T., Roubtsova, T., Coggeshall, M., Ford, T. M., Grauke, L. J., Graves, A. D., Leslie, C. A., McKenna, J., Woeste, K., Yaghmour, M. A., Cranshaw, W., Seybold, S. J., Bostock, R. M., and Tisserat, N. 2013. Susceptibility of walnut and hickory species to Geosmithia morbida. Plant Dis. 97:601-607.

Thousand cankers disease (TCD) of walnut is a result of feeding in the phloem by the walnut twig beetle (WTB), Pityophthorus juglandis, and subsequent canker formation caused by Geosmithia morbida around galleries. TCD has caused extensive morbidity and mortality to Juglans nigra in the western United States and, in 2010, was discovered in the eastern United States, where the tree is a highly valuable timber resource. WTB and G. morbida also have been found in J. regia orchards throughout major production areas in California, and the numbers of damaged trees are increasing. We tested the susceptibility of walnut and hickory species to G. morbida in greenhouse and field studies. Carya illinoinensis, C. aquatica, and C. ovata were immune. All wal-

nut species tested, including $J$. ailantifolia, J. californica, J. cinerea, $J$. hindsii, J. major, J. mandshurica, J. microcarpa, J. nigra, and J. regia, developed cankers following inoculation with G. morbida. J. nigra was the most susceptible, whereas J. major, a native host of the WTB and, presumably, G. morbida, had smaller and more superficial cankers. Canker formation differed among maternal half-sibling families of $J$. nigra and $J$. cinerea, indicating genetic variability in resistance to $G$. morbida. Our inoculation studies with G. morbida have corroborated many of the field observations on susceptibility of walnut and hickory species to TCD, although the ability of the WTB to successfully attack and breed in walnut is also an important component in TCD resistance.
\end{abstract}

Juglans nigra, commonly called black walnut or eastern black walnut, is one of the most highly valued timber species in North America. The wood is prized for use in cabinetry, gunstocks, and other finished wood products; the nuts are an important nutritional source for wildlife; and the nut shells are used for a variety of industrial applications $(17,26)$. The greatest volume of black walnut growing stock on timberland is found in Missouri, Ohio, Iowa, Indiana, Illinois, Tennessee, West Virginia, Kansas, Pennsylvania, Virginia, and Michigan (18,26). In addition to the multimillion dollar U.S. market for walnut wood, walnut lumber and logs are exported internationally to over 45 countries $(31,33)$.

J. nigra is not native to the western United States but it has been widely planted there as an ornamental and nut-bearing tree and, to a limited extent, for wood products. In the early 1990s, J. nigra mortality was observed in Oregon and Utah but the cause was not determined (22,30). Subsequent death of J. nigra in the late 1990s in Utah (22) and in 2001 in New Mexico (32) was attributed to drought and attack by the walnut twig beetle (WTB), Pityophthorus juglandis (32). In 2008, J. nigra death in Colorado was determined to be the result of aggressive feeding by the WTB on

\section{Corresponding author: N. Tisserat, E-mail: ned.tisserat@colostate.edu}

Mention of a trademark, proprietary product, or vendor does not constitute a guarantee or warranty of the product by the United States Department of Agriculture and does not imply its approval to the exclusion of other products or vendors that also may be suitable.

Accepted for publication 26 November 2012.

http://dx.doi.org/10.1094/PDIS-07-12-0636-RE

(C) 2013 The American Phytopathological Society large branches and even the trunk and subsequent canker development around beetle galleries caused by a newly described fungal symbiont of the beetle, Geosmithia morbida $(15,29)$. Fusarium solani may also contribute to tree mortality during the latter stages of TCD by forming cankers on the main trunk (29). The disease was given the common name of thousand cankers disease (TCD) because of the enormous number of coalescing cankers that are formed in the bark of severely affected trees (29). The WTB $(5,24)$ and TCD $(30)$ are now widespread in J. nigra in the western United States and have caused extensive mortality. The disease recently has become established in the native range of this species in Tennessee, Virginia, and Pennsylvania $(9,13,20,36)$ and poses a potential threat to J. nigra in those states.

Sixteen walnut species are native to the Americas and six of these, including J. californica (southern California black walnut), J. cinerea (butternut), J. hindsii (northern California black walnut), $J$. major (Arizona walnut), J. microcarpa (little walnut), and $J$. nigra have ranges in the United States $(16,28)$ and are potentially at risk from TCD. The WTB is native to J. major in Arizona and New Mexico (2) and, perhaps, to J. californica in California (3) but has expanded its range to include 90 U.S. counties (71 in the west and 19 in the east) in 12 states (24). G. morbida has been consistently isolated from small, superficial cankers surrounding the beetle galleries in J. major throughout its range in Arizona and New Mexico (N. Tisserat, unpublished data) but the fungus has not caused widespread dieback or mortality in this species $(5,11)$ as it has with J. nigra. Similarly, G. morbida has been isolated from WTB galleries in declining $J$. californica and $J$. hindsii in California $(6,25)$ but the relative susceptibility of these species to the fungus from controlled experiments has not been reported previously. TCD has recently been reported in a single $J$. cinerea tree in Oregon (23). The J. cinerea population throughout the 
eastern United States and Canada has been decimated by butternut canker caused by Ophiognomonia clavigignenti-juglandacearum $(1,4,19)$ and further damage or mortality caused by TCD could be serious. Other walnut species exotic to the United States also may be impacted by TCD. J. regia (Persian or English walnut), native to Eurasia, is widely planted in North America and is a commercially important orchard crop in California. G. morbida has been isolated from individual $J$. regia trees exhibiting cankers in California orchards but the potential impact of TCD on this crop is still unknown $(6,12)$. J. ailantifolia (Japanese walnut), introduced into North America from Asia, has become naturalized in areas of the eastern United States and, in some locations, has hybridized with J. cinerea (14).

Numerous hickory species (Carya spp.), also members of the family Juglandaceae, are native to North America and are important ecologically and commercially. For example, Carya illinoinensis (pecan) is native to the southern United States but is widely planted for nuts outside its natural range. In 2011, over 251 million pounds of pecan nuts (in shell) were harvested (30). TCD has not been reported in any hickory species, although the ability of WTB and G. morbida to colonize hickory species without causing significant damage could have important epidemiological consequences (e.g., serving as an inoculum reservoir) because many of their ranges overlap with those of J. nigra and J. cinerea. The objective of this study was to determine the relative susceptibility of selected walnut and hickory species to G. morbida. A preliminary assessment of some species was published (34).

\section{Materials and Methods}

Greenhouse inoculations. For all greenhouse experiments, 1- to 2-year-old dormant trees were planted between February and April in each year in 3.8- or 7.6-liter plastic pots containing a soilless mix (P4, Conrad Fafard, Inc.). Trees were placed on a greenhouse bench at 20 to $25^{\circ} \mathrm{C}$ and allowed to resume growth for at least 1 month prior to inoculation.

G. morbida isolates 1217 (CBS 124663) and 1218 (CBS 124664), originally isolated from J. nigra in Colorado, were used as inocula in all experiments in Colorado. Isolates were grown on half-strength potato dextrose agar ( $1 / 2$ PDA) for approximately 7 days prior to use. For inoculations in all greenhouse experiments, wounds were made in the bark as deep as the xylem in the main stem of each tree by using a 3-mm-diameter metal punch. Wounds were spaced approximately 10 to $15 \mathrm{~cm}$ apart, with the lowest wound on the stem approximately $15 \mathrm{~cm}$ from the tree base. The number of wounds varied with the experiment. Following wounding, bark inside the wound was removed and replaced with $1 / 2$ PDA or $1 / 2$ PDA colonized by one of the G. morbida isolates. Wounds were sealed with Parafilm and trees were placed on the greenhouse bench in a randomized complete block design. Parafilm was removed 3 weeks after inoculation. After 6 weeks, stems were harvested and the outer bark was removed to expose phloem necrosis associated with wounding or canker development. Discolored areas were determined from digital images by using the Java software ImageJ 1.42 (http://rsb.info.nih.gov/ij/index.html). Canker areas that developed following inoculations with G. morbida were compared by paired $t$ tests to areas of discoloration associated with wounds in which $1 / 2$ PDA was inserted. Canker area differences among tree species resulting from G. morbida inoculations were compared by analysis of variance (MINITAB 14) (http://www. minitab.com/en-US/).

In May 2009, walnut and hickory species were obtained from various sources (Table 1). In some cases, the set of trees representing certain species (e.g., C. illinoinensis and J. nigra) were grown from pools of open-pollinated seeds, and, therefore, were not necessarily related to one another. In other species (e.g., $J$. californica), replicate trees were grown from nuts collected from a single parent tree. The set of maternal half-sibling trees representing these species were designated as families. Four wounds were made in the stems of five $C$. ovata (shagbark hickory) trees and six trees each of the other species. Stem diameters were 4 to $11 \mathrm{~mm}$. Bark plugs in wounds second and third from the bottom were removed and replaced with plugs of $1 / 2$ PDA or $1 / 2$ PDA colonized by Aspergillus niger, respectively. This fungus, commonly found in WTB galleries, was included as a control to compare wound discoloration associated with a nonpathogenic fungus to that of G. morbida. Holes at the other two wound sites were filled with $1 / 2$ PDA colonized by one of the two G. morbida isolates, such that each isolate was placed in the top hole on three replicate trees and the bottom hole on three others. In September 2009, a second set of open-pollinated or maternal halfsibling trees representing the same species and collected from the same sources were inoculated and incubated in the same manner.

In May 2010, stems from six arbitrarily selected trees representing six maternal half-sibling J. nigra families supplied by the Hardwood Tree Improvement and Regeneration Center (HTIRC; United States Department of Agriculture [USDA] Forest Service, Purdue University), were wounded in three places. A 1/2 PDA plug was inserted in the bottom wound of each tree and $1 / 2$ PDA plugs colonized by the two G. morbida isolates were randomly placed in the other two wounds. The experiment was repeated in September 2010 by inoculating six additional trees from the same families. In a separate September experiment, but using the same methods, three trees each of $C$. illinoinensis 'Peruque' and 'Riverside' and six trees of C. aquatica (water hickory), obtained from the USDA

Table 1. Canker development in hickory and walnut species 6 weeks after inoculation with Geosmithia morbida in the greenhouse in June and September 2009

\begin{tabular}{|c|c|c|c|c|}
\hline \multirow[b]{2}{*}{ Species } & \multirow[b]{2}{*}{ Genotype $^{z}$} & \multirow[b]{2}{*}{ Source } & \multicolumn{2}{|c|}{ Canker area $\left(\mathrm{mm}^{2}\right)^{\mathrm{y}}$} \\
\hline & & & June & September \\
\hline Carya ovata & Open pollinated & Cold Stream Farm, MI & $4.3 \mathrm{a}$ & \\
\hline C. illinoinensis & Open pollinated & Kansas State Forest Nursery & $12.8 \mathrm{a}$ & $8.6 \mathrm{a}$ \\
\hline Juglans major & Open pollinated & Walnut Creek, AZ & $10.9 \mathrm{a}$ & $28.3 \mathrm{a}$ \\
\hline J. hindsii & Multiple families & National Clonal Germplasm Repository, Davis, CA & $18.9 \mathrm{a}$ & $40.4 \mathrm{ab}$ \\
\hline \multirow[t]{3}{*}{ J. californica } & Family DJUG15.13 & National Clonal Germplasm Repository, Davis, CA & $19.2 \mathrm{a}$ & $111.0 \mathrm{c}$ \\
\hline & Family DJUG20.7 & $\ldots$ & $37.2 \mathrm{ab}$ & $\ldots$ \\
\hline & Family DJUG23.3 & $\ldots$ & $\ldots$ & $72.8 \mathrm{bc}$ \\
\hline J. microcarpa & Open pollinated & Concord, NE & $30.0 \mathrm{a}$ & $19.9 \mathrm{a}$ \\
\hline J. regia & Open pollinated and multiple families & Cold Stream Nursery, TN, University of California, Davis & $36.0 \mathrm{a}$ & $26.0 \mathrm{a}$ \\
\hline J. ailantifolia & Multiple families & University of Tennessee & $66.0 \mathrm{~b}$ & $79.7 \mathrm{c}$ \\
\hline J. cinerea & Multiple families & University of Tennessee & $82.2 \mathrm{bc}$ & $30.4 \mathrm{a}$ \\
\hline J. nigra & Open pollinated & Kansas State Forest Service & $121.3 \mathrm{c}$ & $191.2 \mathrm{c}$ \\
\hline
\end{tabular}

y Means in same columns not followed by the same letter are different $(P=0.05)$ by Fisher's least significant difference test. The area of phloem discoloration caused by $G$. morbida was greater $(P \leq 0.05)$ in all species except $C$. ovata in June and $C$. illinoinensis in June and September than discoloration surrounding wounds in which half-strength potato dextrose agar was inserted.

${ }^{\mathrm{z}}$ Maternal half-sibling trees within a family were grown from nuts collected from a single tree. In the case where only two or three individuals of a family were obtained, trees from multiple families were arbitrarily selected for each experiment. Trees were 1 to 2 years old (4 to 11 mm in stem diameter) at the time of inoculation. 
Agricultural Research Service (ARS) Pecan Breeding \& Genetics collection, and six trees in each of nine maternal half-sibling $J$. nigra families, obtained from the University of Missouri, were inoculated with G. morbida. The experiment was not repeated.

Six trees each in nine $J$. cinerea and three hybrid (J. cinerea $\times$ ailantifolia) families obtained from HTIRC were inoculated in May 2011 and evaluated as previously described, except that only one G. morbida isolate (1217) was used. The experiment was not repeated.

Field inoculations. Colorado. In June 2008, two 3-mm-diameter wounds, spaced approximately $15 \mathrm{~cm}$ apart, were made with a metal punch on each of four to six branches of a single $J$. cinerea, J. mandshurica (Manchurian walnut), and J. microcarpa tree located in the Colorado State University arboretum in Fort Collins). Trees were approximately 20 years old and the diameters of inoculated branches were 7 to $15 \mathrm{~mm}$. The $1 / 2$ PDA or $1 / 2$ PDA colonized by G. morbida isolate 1217 was randomly inserted into a wound on each branch; wounds were wrapped with Parafilm and the film was removed after 3 weeks. Inoculated branches were cut from the trees after 8 weeks and canker areas were determined as previously described.

Utah and Idaho. Field inoculations of walnut and hickory species were conducted in June 2009 at two plantings near Richmond, UT and one planting near Dayton, ID maintained by Improving Perennial Plants for Food and Bioenergy, Inc. (IPPFBE), a 501.c.3 nonprofit corporation. Trees were 1 to 6 years old (field age) and had been planted in blocks (half-sibling families) at one location or were arbitrarily scattered (individual species) at the three locations. The number of trees representing each species or half-sibling family within a species that were inoculated varied from 1 to 5 . Three 3-mm-diameter wounds spaced 10 to $15 \mathrm{~cm}$ apart were made on three branches on each tree using a metal punch. Tree branches were approximately the same size (10 to $20 \mathrm{~mm}$ in diameter) and at the same tree height ( 1 to $2 \mathrm{~m}$ ). The $1 / 2$ PDA was inserted into the center wound and 1/2 PDA colonized with $G$. morbida isolates 1222 and 1223 , originally isolated from $J$. regia and $J$. nigra, respectively, at the IPPFBE, were randomly placed in either the top or bottom wound. Following inoculation, wounds were wrapped with Parafilm; the film was removed after 3 weeks. After 5 weeks, all inoculated branches were removed from the trees and canker areas were determined as previously described. No differences $(P>$ $0.10)$ in canker size between the two isolates on each tree species or family were detected. Therefore, canker areas formed in response to the two isolates were averaged first for each branch, then for all branches on the same tree. Mean canker area for each tree was then used to determine mean canker sizes for each tree species and family, except where only one tree of a species was inoculated. In those cases, mean canker size was determined by averaging canker areas from the three inoculated branches. Inoculations were repeated in June 2011 on some but not all of the same trees. The number of trees representing each species or halfsibling family within a species that were inoculated varied from 1 to 6. The experiment was modified from 2009, such that one branch on each tree (two branches for an individual tree representing a species) was inoculated at three locations with $G$. morbida isolate 1222 as described. The $1 / 2$ PDA was placed in a fourth wound located at the base of each branch. Branches were harvested in November and canker areas for each species were analyzed as previously described. Cankered areas that formed in response to G. morbida on branches within a species or halfsibling family in both years were compared in paired $t$ tests to areas of discoloration in response to wounds treated with $1 / 2$ PDA. Canker sizes among species were not directly compared by analysis of variance because the number of tree replicates for each species and family was variable and trees were scattered across three locations.

California. In 2010, five walnut species (J. ailantifolia, J. californica, J. major, J. microcarpa, and J. regia) from the Juglans Collection of the USDA-ARS National Clonal Germplasm Repository (NCGR), established in 1984 at Winters, CA, were evaluated for susceptibility to G. morbida. On 8 July, three 5-mm-diameter wounds spaced 10 to $15 \mathrm{~cm}$ apart were made with a cork borer into the bark to the xylem on two branches in each of five trees of each walnut species. Branches were 2 to $4 \mathrm{~cm}$ in diameter and 2 to $4 \mathrm{~m}$ above the ground. The $1 / 2$ PDA was inserted into the center wound on each branch, and 1/2 PDA colonized with G. morbida isolates GM-1 and GM-3, originally isolated from J. hindsii and J. regia, respectively, in California were randomly placed in one of the two outer wounds. Wounds were covered with Parafilm for the duration of the experiment. On 19 August, inoculated branches were excised and canker lengths were determined. A second trial on a set of five different trees representing each species was conducted from 21 July to 1 September 2010 . Two additional trials were conducted from 8 July to 19 August and 26 July to 8 September in 2011 in a similar manner, except that five trees representing $J$. hindsii and $J$. mandshurica were also included at each date. To the extent possible, the same groups of trees representing each species were used in both years. In all trials, the length of discoloration associated with wounds filled with $1 / 2$ PDA was subtracted from bark necrosis associated with $G$. morbida inoculations. Lesion length data were $\log _{10}$ transformed to establish a normal distribution and then analyzed as a mixed model with PROC MIXED (SAS ver. 9.1; SAS Institute). Walnut species was treated as a fixed effect, while year, trial, isolate, and replicate tree were treated as random effects.

\section{Results}

Greenhouse inoculations. Canker formation in walnut and hickory species in the 2009 experiment was not influenced $(P>$ 0.10 ) by $G$. morbida isolate or by the position of inoculation on the stem; therefore, data were pooled for analysis in both experiments (Table 1). However, differences in canker development in some species were observed between the two experiments and those results are presented separately. No cankers developed in $C$. illinoinensis and $C$. ovata following inoculation with $G$. morbida. After 6 weeks, wounds had sealed and the fungus could not be isolated from the callus. In contrast, cankers developed in all inoculated J. nigra trees. Cankers, sometimes reaching $12 \mathrm{~cm}$ in length, often were irregular in shape with small, finger-like streaks of necrotic phloem radiating from their margins. These cankers were similar to those observed in naturally infected branches. $G$. morbida was consistently isolated from canker margins in these trials. Reactions of other walnut species to inoculations with $G$. morbida were variable. J. californica, J. hindsii, J. major, J. microcarpa, and $J$. regia developed small cankers in both experiments and they were larger $(P<0.05)$ than the area of discoloration associated with wounds in which $1 / 2$ PDA had been inserted. $G$. morbida was consistently isolated from discolored tissue in these species. In general, $J$. cinerea (except in the second experiment) and $J$. ailantifolia developed larger cankers than the other walnut species, except $J$. nigra. Inoculation of trees with A. niger, a common nonpathogenic inhabitant of necrotic J. nigra bark, did not result in greater phloem discoloration $(P>0.10)$ than wounds in which $1 / 2$ PDA had been inserted.

There were no isolate or experiment interaction effects $(P>$ 0.10 ) on canker development following inoculation of J. nigra trees representing maternal half-sibling families from the HTIRC in 2010; therefore, data from these experiments were combined for analysis. Cankers formed in all trees and differences $(P<0.05)$ among maternal half-sibling families were observed. Canker areas in the most susceptible family were approximately $50 \%$ larger, on average, than the least susceptible family (Fig. 1). In a similar experiment in the same year, J. nigra families from the University of Missouri exhibited variation in mean canker size (Fig. 2). No cankers developed in C. aquatica or two varieties of $C$. illinoinensis in this experiment. In the experiment conducted in 2011, J. cinerea and its hybrids with $J$. ailantifolia also exhibited variation in canker development (Fig. 3). Cankers in OS 60R were only slightly larger $(P<0.05)$ than wound discoloration alone. Trees in other maternal half-sibling families had larger cankers, especially those representing $J$. cinerea hybrids. 
Field inoculations. Colorado Cankers formed on branches of $J$. microcarpa $\left(169 \mathrm{~mm}^{2}\right)$, J. cinerea $\left(206 \mathrm{~mm}^{2}\right)$, and J. mandshurica $\left(564 \mathrm{~mm}^{2}\right) 8$ weeks after inoculation with G. morbida. Bark necrosis surrounding branch wounds inoculated with $G$. morbida in each tree was greater $(P<0.05)$ than wounds in which $1 / 2$ PDA had been inserted. G. morbida was consistently isolated from canker margins on each tree in this trial.

Utah. Juglans and Carya spp. planted at the IPPFBE sites exhibited variable susceptibility to G. morbida in 2009 (Fig. 4). C. illinoinensis, C. ovata, and J. ailantifolia did not develop cankers; wounds had sealed with callus after 5 weeks and G. morbida could not be isolated. J. major and J. nigra $\times$ regia had small necrotic lesions surrounding inoculation sites but these were not larger $(P>$ $0.10)$ than discoloration associated with the wounding process. Nevertheless, G. morbida was isolated from canker margins in each species. Similarly, J. hindsii and J. regia developed small cankers from which G. morbida could be isolated. Successively larger cankers were found in J. microcarpa and in maternal halfsibling families of J. nigra.

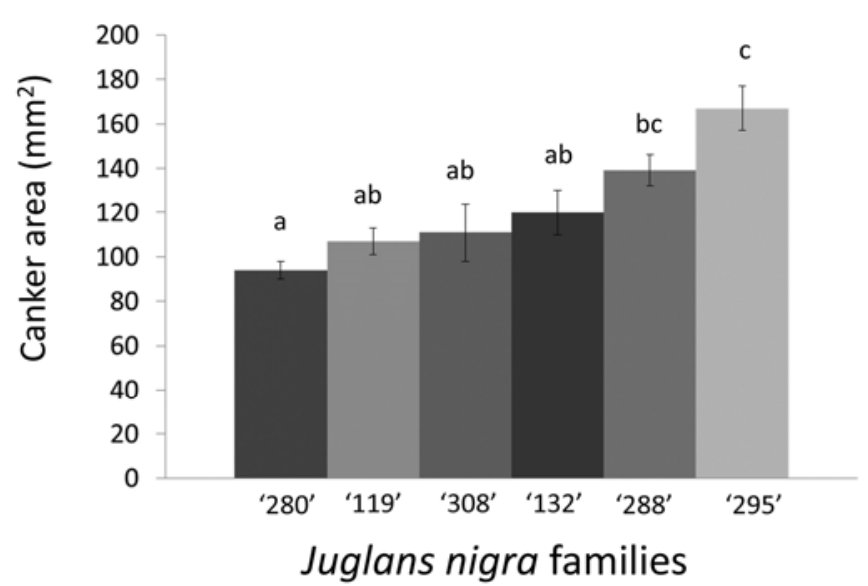

Fig. 1. Canker development in Juglans nigra trees representing maternal halfsibling families 6 weeks after inoculation with Geosmithia morbida in the greenhouse in 2010. Column means not followed by the same letter are different $(P=$ 0.05 ) by Fisher's least significant difference test and represent canker areas averaged across two G. morbida isolates and two experiments. Bars indicate standard errors.

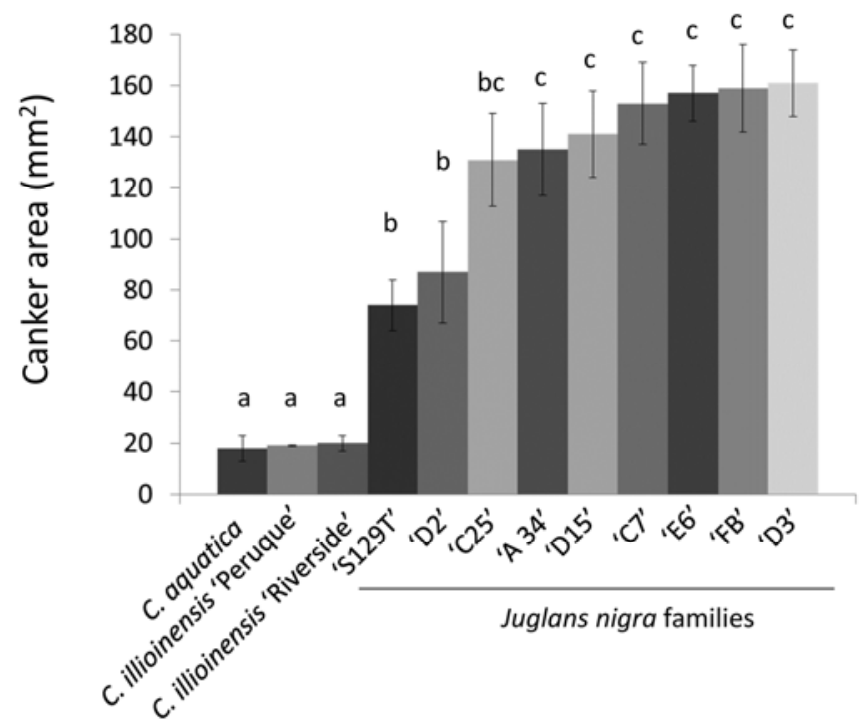

Fig. 2. Canker development in Carya aquatica, C. illinoinensis, and Juglans nigra trees representing maternal half-sibling families 6 weeks after inoculation with Geosmithia morbida in the greenhouse in 2010. Column means not followed by the same letter are different $(P=0.05)$ by Fisher's least significant difference test and represent canker areas averaged for two G. morbida isolates. Bars indicate standard errors.
Results from the 2011 Utah inoculations were similar to 2009 (Fig. 5), except that canker areas tended to be larger in most species as a result of the longer period between inoculation and canker assessment (June to November). No or very little canker formation was observed in C. illinoinensis, C. ovata, or J. major. Small but significant $(P<0.05)$ areas of necrotic phloem developed at inoculation sites in J. regia, J. hindsii, and J. nigra $\times$ regia and G. morbida was isolated from canker margins in this trial. Cankers developed in all J. microcarpa and J. nigra trees and variation in canker area was observed among the J. nigra families representing the different nut cultivars

California. All walnut species tested at the NCGR developed cankers and G. morbida was consistently isolated from canker margins in these trials. There was no effect $(P>0.10)$ of experi-

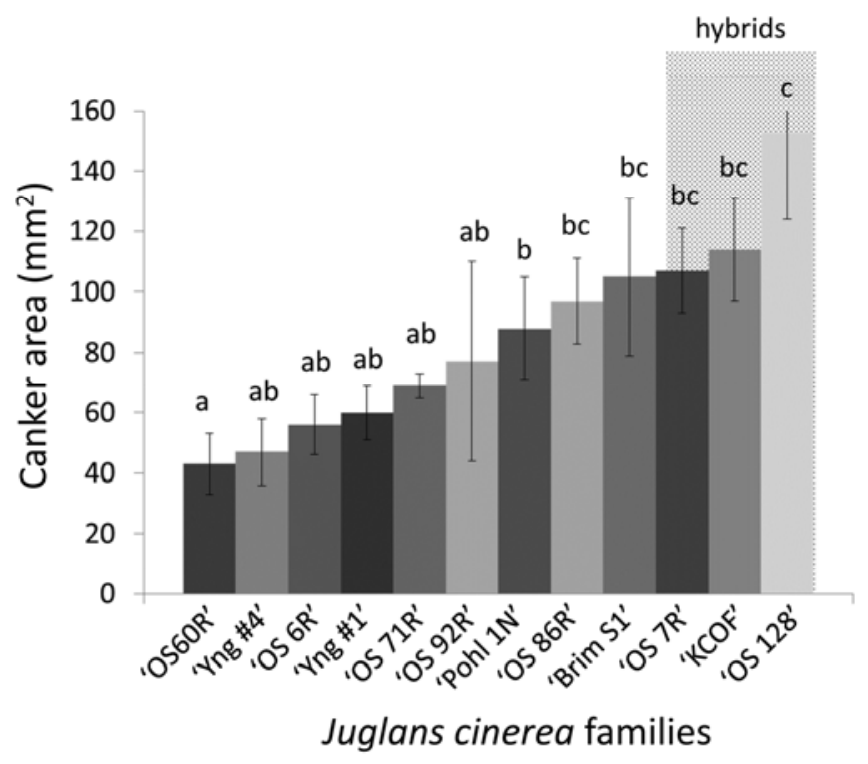

Fig. 3. Canker development in Juglans cinerea and J. cinerea $\times$ ailantifolia hybrid (shaded columns) trees representing maternal half-sibling families 6 weeks after inoculation with Geosmithia morbida in the greenhouse in 2011. Column means not followed by the same letter are different $(P=0.05)$ by Fisher's least significant difference test and represent canker areas averaged for two fungal isolates. Bars indicate standard errors.

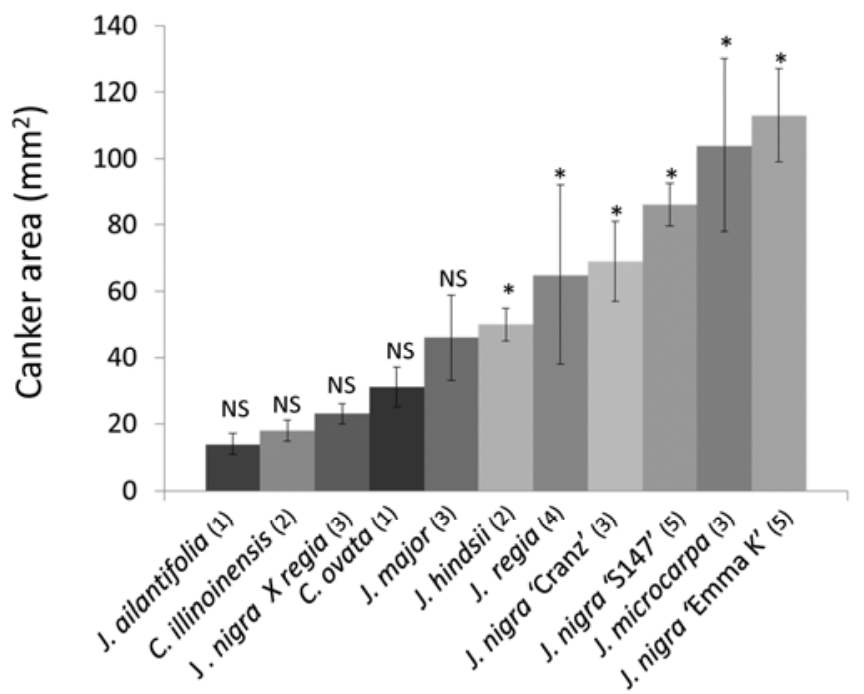

Fig. 4. Canker development in branches of hickory and walnut species 5 weeks after inoculation with Geosmithia morbida at the Improving Perennial Plants for Food and Bioenergy, Inc. field planting, Utah, in May 2009. Bars represent standard errors; * $(P \leq 0.05)=$ significant and NS $(P>0.10)=$ nonsignificant differences in bark necrosis around wounds inoculated with $G$. morbida compared with wounds amended with half-strength potato dextrose agar. Numbers in parentheses following species or family name represent the number of replicate trees inoculated. 
mental trial, year, or their interactions with canker formation. J. californica and J. microcarpa had the longest cankers; J. hindsii, $J$. major, and $J$. regia were intermediate; and J. ailantifolia and $J$. mandshurica with the shortest cankers $(P \leq 0.05$; Fig. 6$)$. There was a small difference $(P=0.005)$ in canker lengths between the two G. morbida isolates, with GM-3 $(27.6 \pm 1.1 \mathrm{~mm})$ more virulent than GM-1(23.2 $\pm 1.1 \mathrm{~mm})$.

\section{Discussion}

TCD is an emerging tree disease in North America that is capable of damaging multiple walnut species. In this study, we provide an initial comparison of a number of native and introduced walnut species as well as several hickory species for the reaction of their phloem to infection by G. morbida. A number of these species and their hybrids are important for rootstock development in commercial walnut production. Because effective disease management will most likely include deployment of resistant host material, identification of the potential variation in this regard among species and breeding lines is important.

Susceptibility to G. morbida among species of Juglans and Carya was assessed by lesion length (California) or lesion area (Colorado and Utah) following controlled inoculation of defined isolates of G. morbida. All J. nigra tested developed cankers following inoculation with G. morbida and it was the most susceptible of the walnut species. However, differences in canker sizes among maternal half-sibling families in both greenhouse and field trials were identified. In most families, cankers extended from the phloem to the cambium and exhibited irregular margins, with no indication of a host defense response (e.g., callus formation). Cankers in a few families (e.g., 280) were small and superficial, with uniform margins that were bordered by suberized tissue, indicating an induced host defense response. These results support previously observed differences in canker formation among J. nigra families following inoculation with $G$. morbida $(7,8)$. J. nigra families included in our studies represented maternal half-siblings from trees with superior nut, growth, or tree form characteristics; they were not selected based on empirical knowledge of their reaction to $G$. morbida. Thus, variation in canker development among these families was unexpected. Healthy J. nigra free of WTB galleries or cankers have been found in Colorado and Utah in areas severely impacted by TCD (30). Although these surviving trees have not yet been tested for resistance, their presence, along with results of our inoculation trials, suggest that there may be even greater genetic

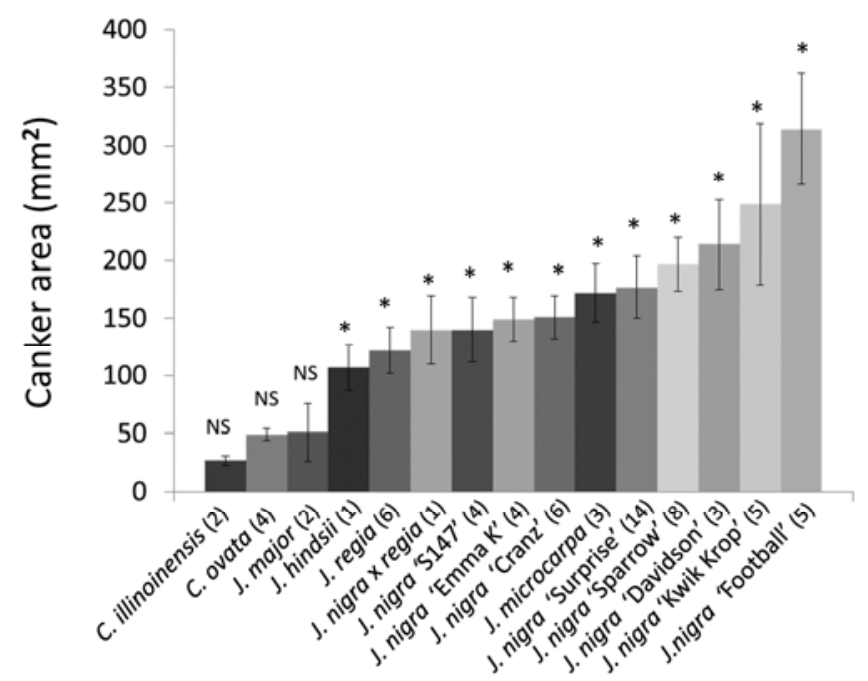

Fig. 5. Canker development in branches of hickory and walnut species 5 months after inoculation with Geosmithia morbida at the Improving Perennial Plants for Food and Bioenergy, Inc. field planting, Utah, in June 2011. Bars represent standard errors; * $(P \leq 0.05)=$ significant and NS $(P>0.10)=$ nonsignificant differences in bark necrosis around wounds inoculated with $G$. morbida compared with wounds amended with half-strength potato dextrose agar. Numbers in parentheses following species or family name represent the number of replicate trees inoculated. differences in J. nigra to canker formation caused by G. morbida. $J$. nigra is an open-pollinated species with high genetic diversity (35). Its range overlaps or is at least contiguous with that of $J$. major and J. microcarpa in the southwestern United States (10). J. major is a native host of the WTB (2) and is less susceptible to $G$. morbida based on our inoculations and field observations. Introgression of resistance genes from $J$. major to $J$. nigra or from $J$. major to J. microcarpa and then to J. nigra via hybridization in this region is plausible. For example, natural hybrids between J. major and $J$. nigra have been observed in Texas (10). Further testing of these hybrids as well as other J. nigra accessions from Texas and throughout eastern North America will provide insights as to possible sources of resistance to G. morbida.

The WTB and G. morbida have not been detected in the native range of $J$. microcarpa in eastern New Mexico (11), even though the beetle and fungus are widely distributed on J. major in the western part of that state. Exploratory surveys in Texas have also yielded no evidence of either organism on J. microcarpa. This was surprising because $J$. microcarpa is susceptible to G. morbida. Furthermore, WTB galleries and natural cankers caused by $G$. morbida have been observed in J. microcarpa at the NCGR planting at Winters, CA, and this species proved to be among the most susceptible of the seven species tested there (Fig. 6). It is possible that $J$. microcarpa is isolated geographically from the native range of WTB and, hence, G. morbida in New Mexico, although both the beetle and G. morbida were collected from a J. major tree located in Lincoln County, NM and within the native range of J. microcarpa (A. D. Graves, unpublished data). Alternatively, in native habitats, the WTB may have difficulty locating and colonizing $J$. microcarpa or the beetle may be unable to complete its life cycle on this host. In any case, further surveys for the presence of WTB and G. morbida throughout the native range of J. microcarpa, including Texas, Oklahoma, and Kansas, are needed.

TCD was recently confirmed in a naturally infected $J$. cinerea in Oregon (23) and, therefore, poses a potential threat to this species in its native range. Our results support the general susceptibility of this species to G. morbida, although some half-sibling families were resistant. There was a trend for half-siblings of $J$. cinerea hybridized with $J$. ailantifolia to be more susceptible to G. morbida and further testing is needed to verify this observation. If true, this could be important because $J$. ailantifolia is being used in butternut breeding programs as a potential source of resistance to the butternut canker pathogen (37).

In greenhouse trials, trees of both $J$. californica and $J$. hindsii developed cankers following inoculation by G. morbida but not to

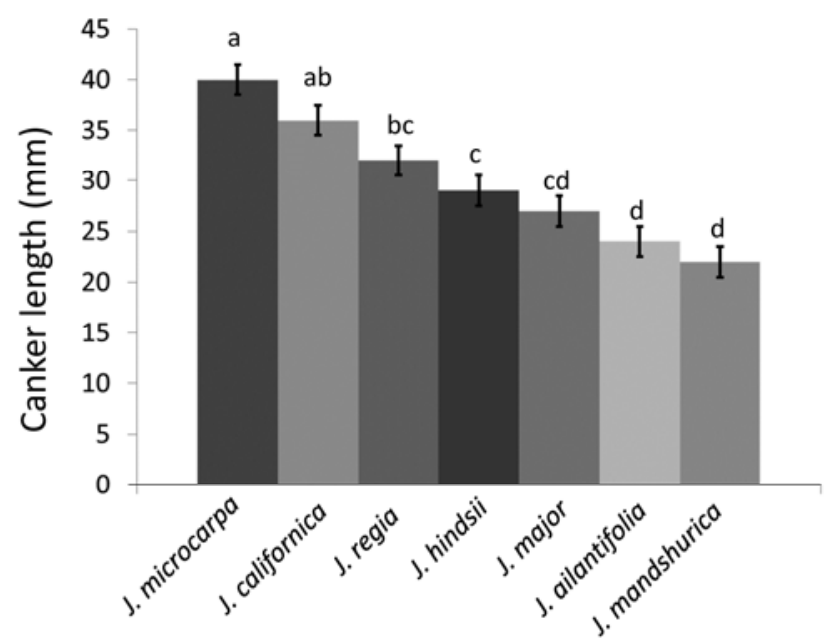

Fig. 6. Canker development in branches of seven walnut species 6 weeks after inoculation with Geosmithia morbida at the United States Department of Agriculture-Agricultural Research Service National Clonal Germplasm Repository, California, in the summers of 2010 and 2011. Column means not followed by the same letter are different $(P=0.05)$ by Fisher's least significant difference test and represent canker lengths averaged for two fungal isolates. Bars indicate standard errors. 
the same extent as J. nigra. The WTB was first collected in California from J. californica in Los Angeles County in 1959 (3) and, since 2008, the insect and G. morbida have been widely collected on this species in southern California $(6,24,25)$. Thus, G. morbida may have always been associated with $J$. californica, causing cankers and contributing to branch dieback of stressed trees attacked by the WTB much in the same manner it does on J. major. The WTB and G. morbida are also widespread on declining J. hindsii in the lower Sacramento Valley $(6,24,25)$, although other factors, including mistletoe and drought, may be contributing to the general dieback in this region. Rapid mortality in J. hindsii, similar to what is occurring in $J$. nigra, has not been observed, perhaps due, in part, to the lower aggressiveness of G. morbida on this host. Nonetheless, among the species tested, both J. californica and J. hindsii were relatively susceptible to $G$. morbida in branch inoculation trials at the NCGR (Fig. 6).

J. regia developed cankers following inoculation with G. morbida but its susceptibility varied depending on experiment. These results are consistent with field observations. For example, two $J$. regia trees naturally infected with TCD were killed in Colorado in 2010 but healthy $J$. regia were found adjacent to J. nigra killed by TCD in Richmond, UT in the same year. The WTB and G. morbida also have been found in J. regia trees in orchards throughout the major production areas of California's Sacramento and San Joaquin Valleys, and the numbers of damaged trees that have been identified are increasing. Nevertheless, widespread mortality of $J$. regia in California has not yet occurred and the potential threat of TCD in commercial orchards is still being assessed. J. regia trees often are grafted onto a walnut hybrid root stock called 'Paradox'. Paradox is commonly defined as a hybrid between $J$. hindsii and $J$. regia but may also include hybrids between J. nigra or J. californica and $J$. regia (21). We tested only a few J. nigra $\times$ regia hybrids in Utah and their reaction varied from not forming cankers in one year to formation of small cankers in the next. It is likely that Paradox rootstocks will show substantial variation in susceptibility to G. morbida depending on parentage, especially if $J$. nigra is used as one of the parents. Further screening of commercial hybrid rootstocks is warranted.

We did not exhaustively test hickory species for susceptibility to G. morbida; however, C. illinoinensis, C. aquatica, and C. ovata did not develop cankers following inoculation, nor were we able to isolate G. morbida from the callus surrounding wounds. These results are consistent with field observations in Colorado and California, where mature $C$. ovata and $C$. illinoinensis appeared healthy, with no evidence of WTB galleries or cankers even though they were growing next to J. nigra (Colorado) and J. hindsii (California), respectively, with advanced symptoms of TCD. This indicates that these species and, perhaps, all hickory species will not be susceptible to G. morbida or likely to serve as an inoculum reservoir as certain oak species do for the chestnut blight fungus (27).

Our inoculation studies with G. morbida have corroborated many of the field observations on susceptibility of walnut and hickory species to TCD. One caveat is that G. morbida is incapable of killing walnut species, even the highly susceptible J. nigra, on its own. In nature, individual cankers caused by G. morbida rarely exceed $20 \mathrm{~cm}$ in length and, even though the fungus produces enormous numbers of dry conidia that could be airborne, there is no direct evidence that infection occurs anywhere on trees except at WTB feeding sites or in and around galleries. Thousands of coalescing cankers resulting from inoculations by the WTB are necessary to kill a mature tree. Therefore, the ability of the WTB to successfully find, colonize, and breed in walnut trees is also an important component in TCD resistance in Juglans spp. or genotypes. Ongoing research at the NCGR is documenting the potential for differential host selection behavior by the WTB on many walnut species.

\section{Acknowledgments}

This research was supported by funds provided by the USDA NIFA Western Region Integrated Pest Management Center and Critical Issues-Emerging and
New Plant and Animal Pests and Diseases grant programs, the USDA Forest Service Forest Health Monitoring Program (Detection Monitoring grant number INT-DM-09-01 and Evaluation Monitoring grant number INT-EM-B-11-03), the USDA-ARS National Germplasm Repository Collection Evaluation Program, and the University of California Agriculture and Natural Resources Competitive Grants Program (number 11-1025). We thank J. Preece and H. Garrison (both USDA-ARS) for research access to the NCGR Juglans collection; S. Schlarbaum, University of Tennessee, for providing germplasm; and L. Holder, R. Feild, M. Shenk, M. Zerillo, and E. Freeland for providing technical support.

\section{Literature Cited}

1. Anderson, R. L., and LaMadeleine, L. A. 1978. The distribution of butternut decline in the eastern United States. U.S. Dep. Agric. For. Serv. Rep. S-378.

2. Blackman, M. W. 1928. The genus Pityophthorus Eichh. in North America: a revisional study of the Pityophthorini, with descriptions of two new genera and seventy-one new species. Bull. N.Y. State Coll. For. Tech. Publ. No. 25.

3. Bright, D. E., and Stark, R. W. 1973. The Bark and Ambrosia Beetles of California (Scolytidae and Platypodidae), Volume 16. Univ. Calif. Berkeley Bull. Calif. Insect Surv. University of California Press, Berkeley.

4. Broders, K. D., and Boland, G. J. 2011. Reclassification of the butternut canker fungus, Sirococcus clavigignenti-juglandacearum, into the genus Ophiognomonia. Fungal Biol. 115(1):70-79.

5. Cranshaw, W. 2011. Recently recognized range extensions of the walnut twig beetle, Pityophthorus juglandis Blackman (Coleoptera: Curculionidae: Scolytinae), in the Western United States. Coleopterist Bull. 65:48-49.

6. Flint, M. L., Graves, A. D., and Seybold, S. J. 2010. Thousand cankers disease of walnuts spreads in California. CAPCA Advisor Mag. 8:36-39.

7. Freeland, E. 2012. Intraspecific variability of Geosmithia morbida, the causal agent of thousand cankers disease, and effects of temperature, isolate and host family (Juglans nigra) on canker development. M.S. thesis, Colorado State University, Ft. Collins.

8. Freeland, E., Cranshaw, W., and Tisserat, N. 2012. Effect of Geosmithia morbida isolate and temperature on canker development in black walnut. Plant Health Progress. Online publication. doi:10.1094/PHP-2012-0618-01RS

9. Grant, J. F., Windham, M. T., Haun, W. G., Wiggins, G. J., and Lambdin, P. L. 2011. Initial assessment of thousand cankers disease on black walnut, $J u$ glans nigra, in eastern Tennessee. Forests 2:741-748.

10. Grauke, L. J., Thompson, T. E, and Mendoza-Herrera, M. A. 2012. Native walnuts of Texas. Acta Hortic. 948:199-210.

11. Graves, A. D., Coleman, T. W., and Seybold, S. J. 2011. Monitoring walnut health and decline in response to thousand cankers disease and infestation by the walnut twig beetle, Pityophthorus juglandis, in southern California and New Mexico. Year One Progress Report for USDA Forest Service Forest Health Monitoring Project INT-EM-B-11-03. http://fhm.fs.fed.us/ em/funded/12/INT-EM-B-11-03.pdf

12. Hasey, J. K., Bostock, R. M., and Michailides, T. J. 2010. Thousand cankers disease of walnut: status in California. (Abstr.) Phytopathology 100:S48.

13. Haun, G., Powell, S., Strohmeier, C., and Kirksey, J. 2010. State of Tennessee Thousand Cankers Disease Action Plan, October. http://www.tn.gov/ agriculture/publications/regulatory/TN_TCD_ActionPlan.pdf

14. Hoban, S., McCleary, T. S., Schlarbaum, S. E., and Romero-Severson, J. 2009. Geographically extensive hybridization between the forest trees American butternut and Japanese walnut. Biol. Lett. 5:324-327.

15. Kolařík, M., Freeland, E., Utley, C., and Tisserat, N. 2011. Geosmithia morbida sp. nov. a new phytopathogenic species living in symbiosis with the walnut twig beetle (Pityophthorus juglandis) on Juglans in the USA. Mycologia 103:325-332.

16. McGranahan, G., and Leslie, C. 1990. Walnuts (Juglans). Pages 907-951 in: Genetic Resources of Temperate Fruit and Nut Crops, Vol II. J. N. Moore and J. R. Ballington, eds. International Society for Horticultural Science, Wageningen, The Netherlands.

17. Michler, C. H., Pijut, P., and Woeste, K. 2006. Black walnut. Pages 189-198 in: Forest Trees, Volume 7. Series title: Genome Mapping and Molecular Breeding in Plants. C. R. Kole, ed. Springer, Heidelberg, Berlin, New York, Tokyo.

18. Moltzan, B. D. 2011. National Response Framework for Thousand Cankers Disease (TCD) on Walnut. USDA Forest Service, USDA APHIS, National Association of State Foresters, and the National Plant Board. USDA Forest Service. http://www.aphis.usda.gov/plant_health/plant_pest_info/tcd/down loads/NationalResponseFramework.pdf

19. Ostry, M. E., and Woeste, K. 2004 Spread of butternut canker in North America, host range, evidence of resistance within butternut populations and conservation genetics. Pages 114-120 in: Black Walnut in a New Century. Proc. 6th Walnut Counc. Res. Symp. Gen. Tech. Rep. NC-243. C. H. Michler, P. M. Pijut, J. Van Sambeek, M. Coggeshall, J. Seifert, K. Woeste, and R. Overton, eds. U.S. Dep. Agric. For. Serv. North Cent. Res. Stn. St. Paul, MN.

20. Pennsylvania Department of Agriculture. 2011. Agriculture Department Announces Detection of Thousand Cankers Disease in Pennsylvania Trees, Enacts Quarantine to Prevent Spread Retrieved from http://www.agri 
culture.state.pa.us

21. Potter, D., Gao, F., Baggett, S., McKenna, J. R., and McGranahan, G. H. 2002. Defining the sources of Paradox: DNA sequence markers for the North American walnut (Juglans L.) species and hybrids. Sci. Hortic. 94:157-170.

22. Pscheidt, J. W., and Ocamb, C. M., senior eds. 2010. Pacific Northwest Plant Disease Management Handbook. Oregon State Extension Service, Corvalis.

23. Serdani, M. 2012. Butternut-a new host for the walnut twig beetle and thousand cankers disease. NPDN News 7:1-2.

24. Seybold, S. J., Coleman, T. W., Dallara, P. L., Dart, N. L., Graves, A. D., Pederson, L., and Spichiger, S. E. 2012. Recent collecting reveals new state records and the extremes in the distribution of the walnut twig beetle, Pityophthorus juglandis Blackman (Coleoptera: Scolytidae), in the United States. Pan-Pac. Entomol. 88:377-380 .

25. Seybold, S. J., Haugen, D., O'Brien, J., and Graves, A. D. 2011. Thousand cankers disease. U. S. Dep. Agric. For. Serv. Northeastern Area State and Private Forestry Pest Alert NA-PR-02-10. http://www.na.fs.fed.us/ pubs/detail.cfm?id=5225

26. Shifley S. R. 2004. The black walnut resource in the United States. Pages 168-176 in: Black Walnut in a New Century. Proc. 6th Walnut Counc. Res Symp. Gen. Tech Rep. NC-243. C. H. Michler, P. M. Pijut, J. Van Sambeek, M. Coggeshall, J. Seifert, K. Woeste, and R. Overton, eds. U. S. Dep. Agric. For. Serv. North Cent. Res. Stn., St. Paul, MN.

27. Sinclair, W. A., and Lyons, H. H. Diseases of Trees and Shrubs, 2nd ed. Cornell Press, Ithaca, NY.

28. Stone, D. E., Oh, S., Tripp, E. A., Rīos, G., and Manos, P. S. 2009. Natural history, distribution, phylogenetic relationships, and conservation of Central American black walnuts (Juglans sect. Rhysocaryon). J. Torr. Bot. Soc. $136: 1-25$.

29. Tisserat, N., Cranshaw, W., Leatherman, D., Utley, C., and Alexander, K. 2009. Black walnut mortality in Colorado caused by the walnut twig beetle and thousand cankers disease. Plant Health Progress. Online publication. doi:10.1094/PHP-2009-0811-01-RS

30. Tisserat, N., Cranshaw, W., Putnam, M. L., Pscheidt, J., Leslie, C. A., Murray, M., Hoffman, J., Barkley, Y., Alexander, K., and Seybold, S. J. 2011. Thousand cankers disease is widespread in black walnut in the western United States. Plant Health Progress. Online publication. doi:10.1094/PHP2011-0630-01-BR

31. USDA-FAS. 2005. Foreign Agricultural Service Export Commodity Aggregations. Department of Commerce, U. S. Census Bureau, Foreign Trade Statistics. http://www.fas.usda.gov/ffpd/US_Exports_Trade_Data/Archived _Exports_Trade_Data/2000-2005/A_Qcomm_sbgrps.pdf

32. USDA Forest Service. 2002. Forest Insect and Disease Conditions of the Southwestern Region, 2001. USDA-FS Southwestern Region, Forestry and Forest Health Publ. R3-02-01.

33. USDA-NASS. 2011. Crop Production 2011. http://search.usda.gov/ search?q=cache:laSV_w0lIgcJ:http://usda.mannlib.cornell.edu/usda/nass/Cr opProd/2010s/2011/CropProd-10-12-2011.pdf+pecans\&proxystylesheet= usda\&output=xml_no_dtd $\&$ access $=$ p $\&$ client $=$ usda $\&$ num $=10 \&$ site $=u s d a \& i$ $\mathrm{e}=\mathrm{UTF}-8$

34. Utley, C., Cranshaw, W., Seybold, S., Graves, A., Leslie, C., Jacobi, W., and Tisserat, N. 2009. Susceptibility of Juglans and Carya species to Geosmithia; a cause of thousand cankers disease. (Abstr.) Phytopathology 99:S133.

35. Victory, E. R., Glaubitz, J. C., Rhodes, O. E., Jr., and Woeste, K. E. 2006 Genetic homogeneity in Juglans nigra (Juglandaceae) at nuclear microsatellites. Am. J. Bot. 93:118-126.

36. Virginia Department of Agriculture and Consumer Services. 2011. VDACS-Plant and Pest Services-Thousand Cankers Disease. http:// www.vdacs.virginia.gov/plant\&pest/disease-tcd.shtml

37. Zhao, P., and Woeste, K. 2011. DNA markers identify hybrids between butternut (Juglans cinerea L.) and Japanese walnut (Juglans ailantifolia Carr.). Tree Genet. Genomes 7:511-533. 